\title{
FORMAÇÃO DE DOCENTES DA ESCOLA BÁSICA, ÁLGEBRA E GEOMETRIA: UM ESTUDO NA PERSPECTIVA DA INVESTIGAÇÃO MATEMÁTICA
}

\author{
Sabrina Monteiro ${ }^{1}$ \\ Luis Felipe Pissaia² \\ Patrícia Franzoni ${ }^{3}$ \\ leda Maria Giongo ${ }^{4}$ \\ Márcia Jussara Hepp Rehfeldt ${ }^{5}$ \\ Marli Teresinha Quartieri ${ }^{6}$
}

\section{RESUMO}

O presente relato aborda o planejamento de um conjunto de atividades de Álgebra e Geometría tendo como aportes teóricos o campo da investigação matemática. O projeto de investigação que as gerou tem como objetivo principal problematizar estratégias na resolução de atividades exploratório-investigativas de matemática, elaboradas em estudos conjuntos com grupos de professores dos anos iniciais a fim de examinar quais aprendizagens teóricometodológicas são desencadeadas por eles considerando a relação ensino-aprendizagemavaliação a partir de suas próprias experiências. Os materiais de pesquisa foram emergindo a partir de reuniões semanais de pesquisadores, alunos de graduação, pós-graduação e professores da escola básica. Os resultados apontam para a necessidade de planejamentos conjuntos demandando considerável tempo para discussões teórico-metodológicas.

Palavras-chave: Investigação Matemática. Álgebra. Geometria. Formação Continuada de Professores.

\footnotetext{
1 Sabrina Monteiro: Professora na Rede Pública Municipal (Lajeado/RS), Professora no Governo do Estado do Rio Grande do Sul, Licenciada em Ciências Exatas (UNIVATES, Lajeado/RS), Mestra em Ensino e Doutoranda em Ensino (UNIVATES, Lajeado/RS); sabrinamonteiro1991@gmail.com

2 Doutorando em Ensino - Universidade do Vale do Taquari - Univates; Ipissaia@universo.univates.b 3 Professora de Economia (FURG, Rio Grande/RS), Mestra em Economia (UFPB, João Pessoa/PB), Doutoranda em Ensino (UNIVATES, Lajeado/RS), Bolsista da Coordenação de Aperfeiçoamento de Pessoal em Nível Superior (CAPES); patriciafranzoni@furg.br

${ }^{4}$ Possui graduação em Matemática - Licenciatura Plena pela Fundação Universidade Federal do Rio Grande (FURG), Mestrado e Doutorado em Educação pela Universidade do Vale do Rio dos Sinos (UNISINOS). Atualmente é professora titular da Universidade do Vale do Taquari - Univates de Lajeado, RS, vinculada ao Centro de Ciências Exatas e Tecnológicas; igiongo@univates.br

${ }^{5}$ Mestrado em Administração pela Universidade Federal do Rio Grande do Sul (2001). É doutora em informática na Educação pela Universidade Federal do Rio Grande do Sul (2009). Atualmente atua na Universidade Vale do Taquari - Univates como professora titular; mrehfeld@univates.br

${ }^{6}$ Doutora em Educação (Unisinos). Docente permanente do PPGECE e PPGEnsino da Universidade do Vale do Taquari (Univates) - Lajeado -RS; mtquartieri@univates.br
} 

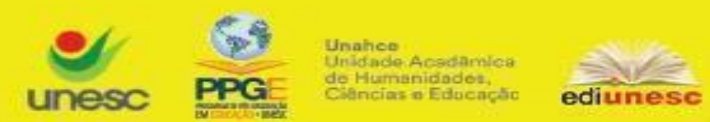

Criar Educação, Criciúma, v. 9, №2, Edição Especial 2020.- PPGE - UNESC - ISSN 2317-2452

\title{
PRIMARY SCHOOL TEACHERS' EDUCATION, ALGEBRA AND GEOMETRY: A STUDY FROM THE PERSPECTIVE OF MATHEMATICAL INVESTIGATION
}

\begin{abstract}
This study approaches the planning of a set of Algebra and Geometry activities, whose theoretical support was the field of mathematical investigation. The main purpose of the investigation that generated them is problematizing the strategies for solving investigativeexploratory mathematical activities, designed in studies connected with groups of teachers of the Yearly Years, focusing on examining which theoretical-methodological learning is triggered by them, by taking into consideration the relationship of teaching-learning-evaluating based on their own experiences. The research material emerged in weekly meetings the researchers attended; the researchers were undergraduate and graduate students and teachers of Primary School. Early results point to the need for combined planning that demands a considerable amount of time for theoretical-methodological discussions.
\end{abstract}

Keywords: Mathematical Investigation. Algebra. Geometry. Continued Teacher Education.

\section{A temática e o referencial teórico}

O relato de experiência expressa o planejamento de atividades de Álgebra e Geometria, com ênfase em investigação matemática, elaboradas a partir de discussões realizadas com o grupo de pesquisadores do projeto "Ensinoaprendizagem-avaliação em Matemática nos Anos Iniciais do Ensino Fundamental: atividades exploratório-investigativas e formação docente". O estudo está sendo desenvolvido em uma universidade gaúcha e conta com apoio financeiro do Conselho Nacional de Desenvolvimento Científico e Tecnológico (CNPq).

Nessa pesquisa estão vinculados docentes da Instituição, mestrandos e doutorandos do Programa de Pós-Graduação em Ensino, bolsistas de Iniciação Científica e professores da Escola Básica, voluntários que foram se agregando ao longo dos anos. Ademais, o grupo de pesquisa conta com a parceria de um grupo de docentes da Universidade Federal do Pará, por meio do grupo de estudos em Educação Matemática e Cultura Amazônica (GEMAZ).

O grupo de pesquisa gaúcho se encontra semanalmente e, dentre as atividades, uma delas consiste em planejar e tarefas exploratórias investigativas, com 


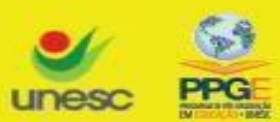

ênfase na Geometria e Álgebra, tendo o intuito de serem, posteriormente, utilizadas em encontros de formação continuada com professores da Escola Básica. Destacase que os encontros são produtivos na medida em que, além da constante interação entre professores da Escola Básica, discentes e pesquisadores da Universidade, as tarefas são criadas e problematizadas em conjunto,. Esta sistemática está diretamente vinculada ao fato de que, posteriormente, as tarefas serão problematizadas com os docentes de uma rede de ensino municipal da região de abrangência da Universidade e, nessa ótica, a colaboração dos docentes da Escola Básica na construção e análise das atividades é fundamental.

A escolha do referencial teórico advindo do campo da investigação matemática está vinculada ao fato da frequente existência de um ensino pautado pelo modelo, quase que exclusivo, da exposição dos assuntos pelo professor, seguido de exemplo e exercício. Embora bastante questionado pela comunidade científica dedicada aos estudos na área da educação matemática, tal modelo ainda é bastante presente no cotidiano das salas de aula. No entanto, metodologias que oportunizam aos estudantes uma ambiência exploratório investigativa, possibilitando a criação de estratégias de enfrentamento de problemas que têm por objetivo aprendizagens de assuntos do âmbito escolar, por vezes não são efetivamente conhecidas pelos professores que ensinam matemática. A formação docente é um meio de viabilizar conhecimento, todavia deve também promover a construção e discussão a partir das práticas dos professores.

As tarefas de Geometria e Álgebra foram selecionadas tendo em vista, por um lado, por prescindirem da diversidade de uso de estratégias para resolução de problemas e consequente aprendizagem matemática. Por outro, os Parâmetros Curriculares Nacionais (BRASIL, 1998, p. 51) já apontavam a importância de ensinar conceitos geométricos, pois, por meio deles, "o aluno desenvolve um tipo especial de pensamento que the permite compreender, descrever e representar, de forma organizada, o mundo em que vive". Além disso, destacam que noções geométricas podem contribuir para a aprendizagem de números e medidas, pois proporcionam ao aluno observar, perceber semelhanças, diferenças e identificar regularidades entre os 


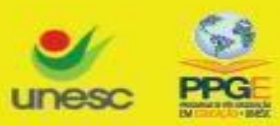

Criar Educação, Criciúma, v. 9, no2, Edição Especial 2020.- PPGE - UNESC - ISSN 2317-2452

objetos do meio em que vive. Nesse mesmo contexto, Kluppel e Brandt (2012, p. 3) afirmam que a "[...] geometria é um campo de conhecimento reconhecido e de inquestionável importância para a formação dos alunos, pois, contribui para o desenvolvimento de um raciocínio geométrico e de habilidades".

Porém, mesmo reconhecendo a importância do ensino de conteúdos geométricos, se observa pouca exploração desses conceitos na prática pedagógica. Barbosa (2008, p. 4) corrobora afirmando que "[...] a geometria quase sempre é apresentada na última parte do livro, aumentando a probabilidade de ela não vir a ser estudada por falta de tempo letivo". Em relação aos anos iniciais do Ensino Fundamental, estudos, como os de Passos (2000), Fonseca (2011), Nacarato e Passos (2003) também destacam o déficit na carga horária destinado para ensinar conteúdos geométricos para os alunos desse nível de escolaridade. Fonseca (2011) pontua que os professores, geralmente, não compreendem como e o que ensinar sobre a Geometria, além das habilidades que se pode desenvolver com esse tema.

Além das dificuldades quanto aos conceitos geométricos, outro entrave com relação ao ensino está na Álgebra que pode ou deveria ser ensinada desde os anos iniciais. Destacamos a importância do ensino da Álgebra na educação básica por meio do comentário de Usiskin (1995, p. 21):

Já não cabe classificar a Álgebra apenas como aritmética generalizada, ela continua sendo um veículo para a resolução de problemas, mas é mais do que isso, fornece meios para se desenvolverem e se analisarem relações. É a chave para a caracterização e compreensão das estruturas matemáticas.

Nessa mesma linha argumentativa, os Parâmetros Curriculares Nacionais (BRASIL, 1998, p. 115) expressam que o campo da Álgebra oportuniza "um espaço bastante significativo para que o aluno desenvolva e exercite sua capacidade de abstração e generalização, além de Ihe possibilitar a aquisição de uma poderosa ferramenta para resolver problemas". Abordá-la sem reduzi-la a um aglomerado de aplicações de sinais, de símbolos e de regras pode ser relevante para a melhoria dos processos de ensino e de aprendizagem da matemática. Há de se destacar que há 

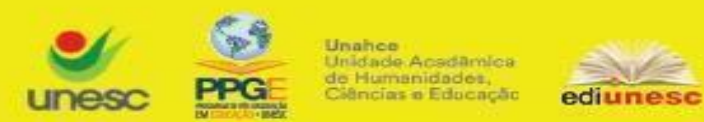

Criar Educação, Criciúma, v. 9, №2, Edição Especial 2020.- PPGE - UNESC - ISSN 2317-2452

um campo produtivo para o desenvolvimento de atividades exploratório-investigativas relacionadas à Álgebra como um propulsor do pensamento algébrico.

Neste sentido, Bredariol e Nacarato (2013, p. 4) comentam que a utilização do pensamento algébrico pode proporcionar o "[...] desenvolvimento da capacidade de generalização por alunos desde o início de seus estudos, pois proporciona a descoberta, possibilitando que os alunos estabeleçam propriedades numéricas ou geométricas". Ademais, utilizar o pensamento algébrico nas mais diferentes situações que se apresentam, abstraindo conceitos costumeiramente trabalhados apenas por meio da aritmética, é um desafio aos envolvidos. Dessa forma,

[...] o ensino de matemática deve visar ao desenvolvimento do pensamento algébrico, por meio da exploração de situações de aprendizagem que levem o aluno a reconhecer que representações algébricas permitem expressar generalizações sobre propriedades das operações aritméticas, traduzir situações-problemas e favorecer as possíveis soluções (BRASIL, 1998, p. 64).

Em consonância ao supracitado, Lins e Gimenez (1997) e Kieran (2004) destacam a relevância do desenvolvimento do pensamento algébrico desse nível de escolaridade. Assim, observa-se que as práticas de ensino podem favorecer o desenvolvimento do pensamento algébrico por meio de situações "que criem oportunidade de as crianças generalizarem padrões aritméticos, estabelecerem relação entre duas grandezas e resolverem problemas com os diferentes termos desconhecidos das operações" (LUNA e SOUZA, 2013, p. 829). Os autores ainda salientam a importância de oportunizarem-se situações de aprendizagem utilizando conhecimentos algébricos desde os anos iniciais, "até então denominados de préálgebra, ampliando-os paulatinamente no decorrer da escolaridade, para uma compreensão algébrica mais estrutural" (LUNA e SOUZA, 2013, p. 832). Estudos de Ponte, Branco e Matos (2009) também destacam a relevância de se trabalhar conteúdos algébricos sob diferentes perspectivas, com análises de gráficos, situações problemas, cálculos de áreas, estudo de geometria e atividades investigativas. 
Partindo desse pressuposto as atividades investigativas contribuem para a integração e socialização. Nessas condições, elas oportunizam um ambiente estimulante e criativo, onde o aluno tem a liberdade de expor seus pensamentos e resoluções aos colegas e ao professor. Nessa perspectiva, Ponte, Brocardo e Oliveira (2003, p.23) salientam que o "[...] envolvimento ativo do aluno é a condição fundamental da aprendizagem". Assim sendo, é de suma importância desenvolver momentos desafiadores, em que o aluno sinta-se motivado a envolver-se durante a atividade.

Skovsmose (2000), também destaca que é importante promover um cenário para investigação que instigue os alunos a formular questões e procurar explicações. Quando os alunos assumem o processo de exploração e explicação, o cenário para investigação passa a constituir um novo ambiente de aprendizagem, onde estes são responsáveis pelo processo. Conforme Brocardo (2001), a realização de investigação na sala de aula pode ajudar a estabelecer um ambiente em que os alunos participam ativamente, facilitando a compreensão dos processos e ideias e da atividade matemática.

Nesta mesma perspectiva Ponte (2003, p. 2) ressalta que:

[...] investigar não significa necessariamente lidar com problemas na fronteira do conhecimento nem com problemas de grande dificuldade. Significa, apenas, trabalhar a partir de questões que nos interessam e que apresentam inicialmente confusas, mas que conseguimos clarificar e estudar de modo organizado.

Assim sendo, investigar relaciona-se a fazer descobertas, explorar problemas e hipóteses, construir argumentos e justificativas que apoiam a ideia. Complementando, o mesmo autor supracitado salienta que investigar é descobrir relações e padrões procurando identificar e comprovar as propriedades levantadas pelo investigador.

Para que uma atividade seja considerada investigativa, conforme Oliveira, Segurado e Ponte (1998), é fundamental que a situação seja motivadora e desafiadora. Levando em consideração a importância do desenvolvimento e 


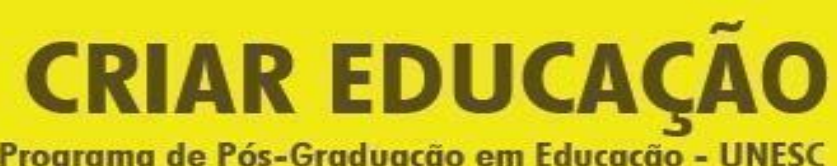

Revista do Programa de Pós-Graduação em Educação - UNESC

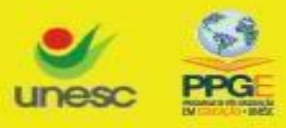

Criar Educação, Criciúma, v. 9, no2, Edição Especial 2020.- PPGE - UNESC - ISSN 2317-2452

envolvimento do aluno nas atividades, Castro (2004, p. 34) destaca que "[...] as aulas investigativas supõe o envolvimento dos alunos com tarefas investigativas que permita a eles realizar atividade matemática". Assim salienta-se a importância do aluno sentirse envolvido durante o processo. Essa investigação pode envolver questões mais abertas com um grau de dificuldade maior ou até questões relativamente simples que surgem na sala de aula. As atitudes desenvolvidas pelos alunos nessas atividades contribuem para mobilizar e consolidar seus conhecimentos matemáticos.

Ponte, Brocardo e Oliveira (2003, p. 23) definem a investigação matemática como uma "atividade de ensino-aprendizagem" que envolve quatro principais momentos. O primeiro momento refere-se ao conhecimento inicial, envolvendo a verificação, análise e a elaboração de questões em referência a situação-problema. O segundo momento envolve a elaboração de ideias e constatações, que se baseia em suposições elaboradas a partir de uma situação, essas hipóteses são chamadas de conjecturas. O terceiro momento implica na realização de testes das conjecturas, na qual será definido se a hipótese fundamenta-se ou não como verdadeira. Ao final, na quarta etapa, ocorre a demonstração e avaliação da situação, sendo que essa sempre deve vir acompanhada de uma argumentação que justifica o seu raciocínio.

Frente a essa constatação Ponte, Brocardo e Oliveira (2003) afirmam que o professor não deve limitar sua metodologia e suas relações na sala de aula com o aluno e com o conteúdo. Para eles é importante que o professor e os alunos tenham autonomia para articular diferentes tipos de tarefas de maneira motivadora para que possa desenvolver o raciocínio matemático em diferentes níveis. Portanto, a relação entre a formação e a prática docente, por meio de grupos de estudos colaborativos entre pesquisadores e professores da educação básica, tem gerado uma ambiência de descoberta sobre as suas práticas de ensino. Outro estudo que corrobora com essa ideia está na tese de Costa (2015), que problematiza sobre a formação docente que por vezes ocorre distante da realidade vivenciada pelos professores.

Muitas vezes percebemos algum distanciamento entre o que os professores compreendem, da formação docente, como relevante para serem incorporadas em 

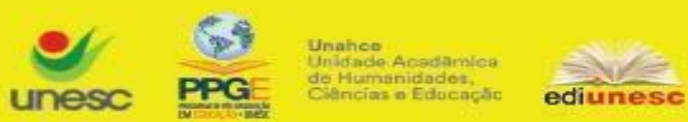

Criar Educação, Criciúma, v. 9, №2, Edição Especial 2020.- PPGE - UNESC - ISSN 2317-2452

suas práticas com fins de melhoria das aprendizagens de seus alunos e o que, efetivamente, fazem. É recorrente, sobretudo, a preocupação destes professores com a mensuração das aprendizagens matemáticas dos alunos. Isso acaba por afastar das práticas dos professores o interesse na elaboração e na realização de atividades investigativas e exploratórias como uma ação contínua para o desenvolvimento de aprendizagens matemáticas. Para Ponte, Brocardo e Oliveira (2003), as atividades de investigação matemática, incentivam o aluno a desenvolver sua autonomia, definindo objetivos e conduzindo a investigação, formulando estratégias, testando suas conjecturas e analisando criticamente os resultados obtidos. Partindo desse pressuposto, não existe uma resposta certa ou errada, seu objetivo é instigar a investigação e discussão das situações propostas.

\section{Tarefas desenvolvidas}

Cabe destacar que as tarefas planejadas são inéditas e envolvem Álgebra, Geometria por meio da investigação matemática. Dentre elas, destacam-se as intituladas sequência de cubos; sequência de cubos empilhados; de diagonais; de triângulos formados a partir de pontos; de tampinhas; de quadriláteros em papel quadriculado; de perímetros de retângulos e de faces, fileira com palitos e jujubas nos palitos. Em especial, neste relato, serão enfatizadas a sequência de diagonais e de triângulos formados a partir de pontos. Cabe destacar que são atividades inéditas, pensadas e muito discutidas pelo grupo de pesquisadores. O planejamento das tarefas ocorreu por meio de discussões e criação de situações-problema de forma coletiva, com um grupo de pesquisadores que reuniram-se por diversas terças-feiras.

Durante a construção das atividades, o trabalho em equipe mostrou-se como uma das principais características do grupo de pesquisa, onde cada participante detentor de sua construção própria de conhecimento foi capaz de compartilhar experiências com a coletividade, a fim de juntos reconstruírem pensamentos e práticas. Anastasiou e Alves (2004) destacam que o desenvolvimento de atividades 


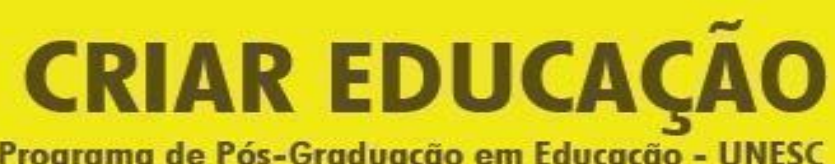

Revista do Programa de Pós-Graduação em Educação - UNESC
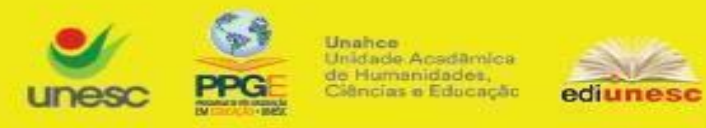

Criar Educação, Criciúma, v. 9, №2, Edição Especial 2020.- PPGE - UNESC - ISSN 2317-2452

em grupo auxilia na construção da autonomia e autoconhecimento, da interação, exposição e contraposição em diferentes situações.

Em função disso, faz-se necessário reforçar a ideia de que trabalhar em um grupo é diferente de fazer parte de um conjunto de pessoas. Neste sentido, as autoras supracitadas mencionam que a realização de atividades em grupo possibilitam a interação, o compartilhar de experiências, o respeito à singularidade e a habilidade de lidar com o outro em sua totalidade, incluindo suas emoções.

O grupo de pesquisadores, pensando em tornar a aprendizagem contextualizada com a realidade escolar, buscou explorar as tarefas por meio da criatividade e colaboração, suscitando algo inédito para a investigação da Álgebra e Geometria para a educação continuada e posterior aplicação em sala de aula. Nesse sentido, a construção das atividades foi minuciosa, sendo necessário além da disponibilidade de tempo, a dedicação, criatividade e persistência dos pesquisadores. Dessa forma cada situação investigativa demandou aproximadamente de um encontro para formulação. Para tanto, vale ressaltar que ao total o grupo desenvolveu 12 atividades. Cabe destacar que, o material utilizado para as atividades foi oriundo das próprias residências dos pesquisadores, sendo reutilizado na composição de objetos que possuem durabilidade e poderão ser utilizados em diferentes situações.

As atividades planejadas de cunho exploratório-investigativas foram alicerçadas pelas quatro etapas descritas por Ponte, Brocardo e Oliveira (2009): a etapa inicial está associada à formulação de questões, possibilitando aos estudantes formular e testar várias conjecturas na segunda etapa. A terceira etapa inclui a realização de testes e refinamento das conjecturas. Por fim, a última etapa diz respeito à argumentação, demonstração e avaliação do trabalho realizado. Na mesma perspectiva, Bandeira e Nehring (2011) destacam a tendência atual da investigação matemática como forma de desenvolver uma aprendizagem baseada na resolução e investigação de situações que possibilitem a estruturação de conjecturas. Dessa forma é possível testá-las, avaliar o raciocínio e justificar os resultados obtidos. Lamonato e Passos (2011) complementam afirmando que investigar está aliado à 


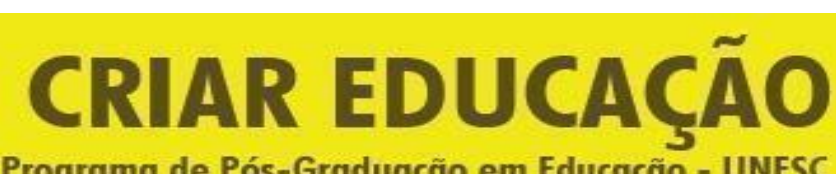

Revista do Programa de Pós-Graduação em Educação - UNESC

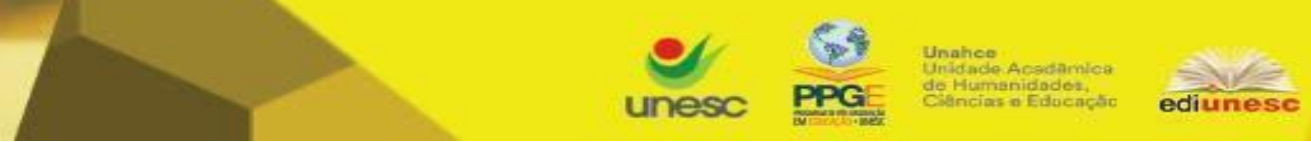

Criar Educação, Criciúma, v. 9, no2, Edição Especial 2020.- PPGE - UNESC - ISSN 2317-2452

ideia de querer saber, procurar, questionar. Portanto, é possível formular questões a partir do reconhecimento de uma situação e da vontade de explorá-la. A seguir serão evidenciadas como as atividades foram construídas.

Atividade 1: Sequência de diagonais

Para o planejamento desta atividade, primeiramente, representou-se algumas figuras geométricas como triângulo, quadrilátero, pentágono, hexágono e heptágono, através da utilização de canudos de plásticos cortados e unidos com fio de lã em seu interior. Posteriormente a esse procedimento, a mesma lã colorida formaria as diagonais de cada figura, unidas em cada vértice onde os canudos desuniam. No entanto, verificou-se que o material utilizado não oferecia a estabilidade necessária para os alunos trabalharem com as diagonais. A Figura 1 ilustra a primeira forma de pensar o material:

FIGURA 1: Construção de diagonais a partir de canudinhos

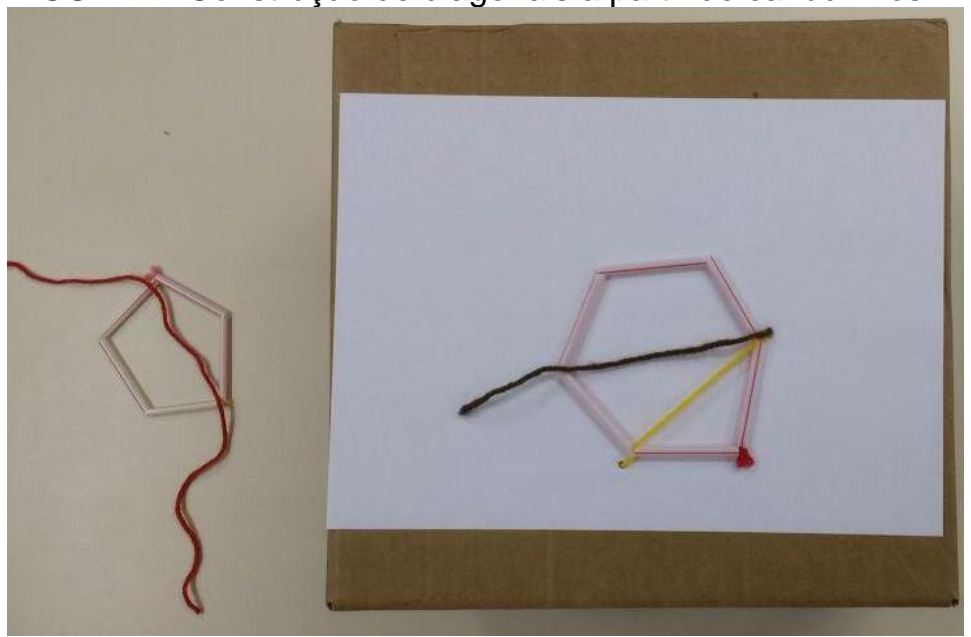

Fonte: Dos autores, 2017.

Em um momento posterior, o grupo propôs outra possibilidade. Dessa forma, uma alternativa encontrada foi desenhar a forma geométrica desejada em pedaços de papelão, realizando furos com agulha de tricô nos vértices para passagem do fio de Iã colorida, que seria utilizada para unir os vértices e compor as diagonais. Observouse que esta forma proposta possibilitaria um melhor entendimento e manuseio aos alunos, além de apresentar-se como um material reciclável, passível de reutilização para atividades futuras. Quanto a contagem das diagonais, cabe destacar que gerou 


\section{CRIAR EDUCAÇÃO}

Revista do Programa de Pós-Graduação em Educação - UNESC

\section{Unesc PPG}

Criar Educação, Criciúma, v. 9, №2, Edição Especial 2020.- PPGE - UNESC - ISSN 2317-2452

bastante discussão, pois a diagonal que liga dois vértices "vai e volta", ou seja, é apenas uma diagonal. Assim, precisa-se levar em consideração que a mesma diagonal passa por dois vértices, por isso chegou-se a generalização que o número de diagonais é dividido por dois.

FIGURA 2: Desenvolvimento da sequência de diagonais

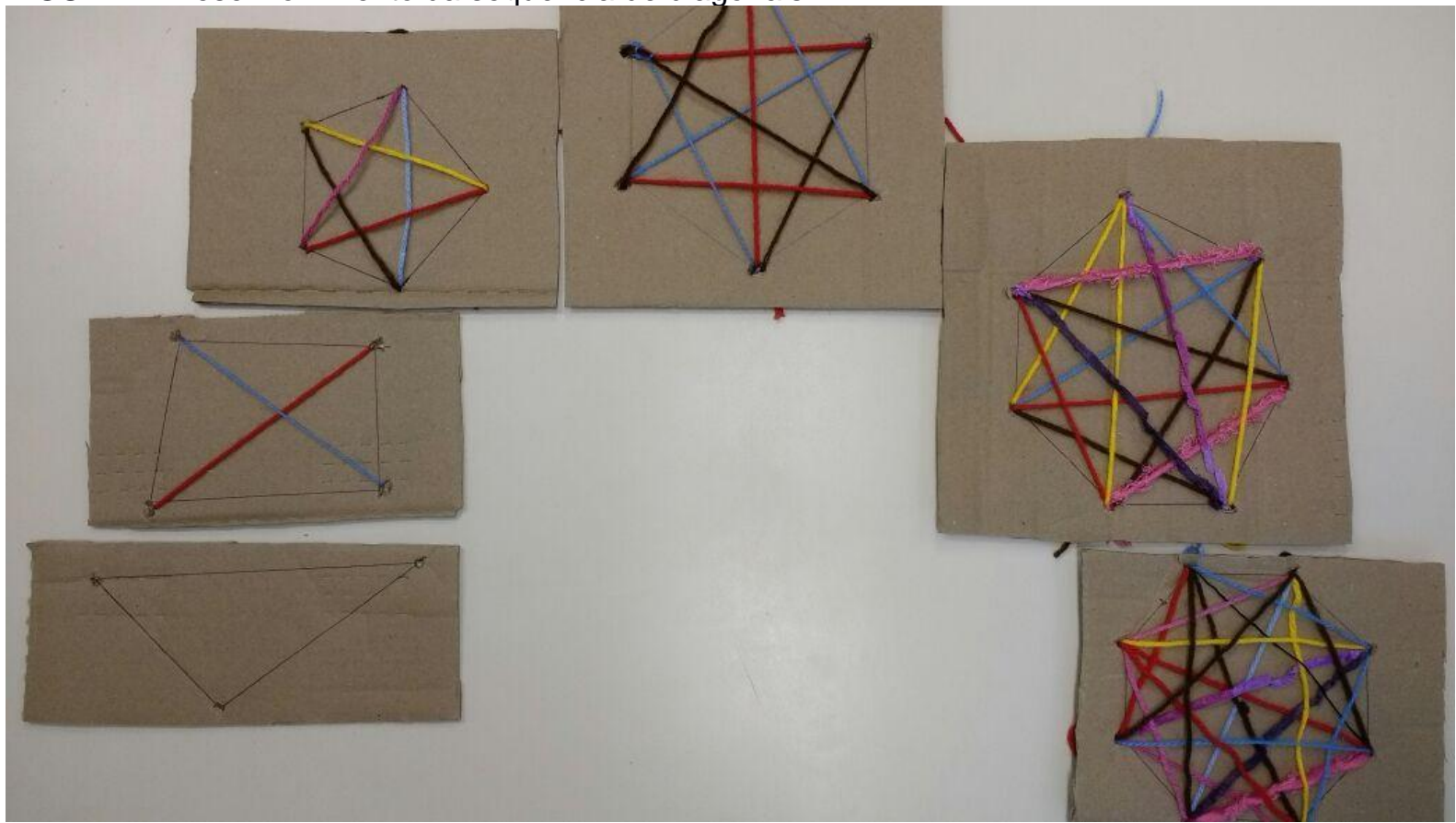

Fonte: Dos autores, 2017.

Após realizar-se a construção das atividades no papelão e com lã, o grupo organizou a atividade escrita para orientar o encontro do grupo de professores participantes dos encontros de formação continuada e posterior aplicação com seus alunos, da seguinte forma:

Atividade: Sequência de diagonais

Observar as figuras geométricas desenhadas no material e disponibilizadas.

a) Fazer o uso dos barbantes e do papelão para representar as diagonais em cada figura. O fio deverá ser inserido em dois vértices não consecutivos e, ao final, preso ou amarrado. Entende-se que os fios representam as diagonais. 


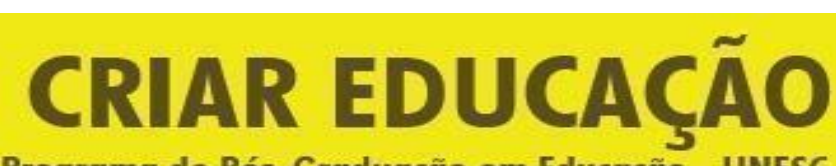

Revista do Programa de Pós-Graduação em Educação - UNESC

Criar Educação, Criciúma, v. 9, no2, Edição Especial 2020.- PPGE - UNESC - ISSN 2317-2452

\begin{tabular}{||c|c|c|c|c|}
\hline \hline & \multicolumn{1}{|c|}{} & & \\
\hline $\begin{array}{c}\text { Figura 1 } \\
\text { Triângulo }\end{array}$ & $\begin{array}{c}\text { Figura 2 } \\
\text { Quadrilátero }\end{array}$ & $\begin{array}{c}\text { Figura 3 } \\
\text { Pentágono }\end{array}$ & $\begin{array}{c}\text { Figura 4 } \\
\text { Hexágono }\end{array}$ & $\begin{array}{c}\text { Figura 5 } \\
\text { Heptágono }\end{array}$ \\
\hline
\end{tabular}

b) Quantas diagonais você representou na figura 1?

c) Quantas diagonais você representou na figura 2?

d) Quantas diagonais você representou na figura 3?

e) Quantas diagonais você representou na figura 4?

f) Quantas diagonais você representou na figura 5?

g) Completar o quadro a seguir utilizando o raciocínio anterior

\begin{tabular}{|c|l|l|}
\hline Figura & Número de lados & Número de diagonais \\
\hline 1 & & \\
\hline 2 & & \\
\hline 3 & & \\
\hline$\ldots$ & & \\
\hline
\end{tabular}

Atividade 2: Triângulos formados a partir de pontos

Partindo de um retângulo de papelão contendo um furo, essa atividade foi desenvolvida com o intuito de formar o menor número de triângulos possíveis, ligando o furo representado até um vértice, depois dois furos, três furos e assim por diante. Dessa forma, primeiramente foi desenvolvida utilizando pedaços de papelão, realizando furos com agulha de tricô nos vértices para passagem do fio de lã colorida, que seria utilizado para unir os vértices e formar os triângulos, conforme mostra a Figura 3:

FIGURA 3: Desenvolvimento da sequência de pontos 


\section{CRIAR EDUCAÇÃOO}

Revista do Programa de Pós-Graduação em Educação - UNESC

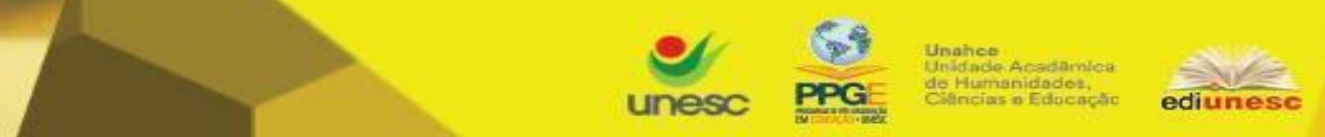

Criar Educação, Criciúma, v. 9, n²2, Edição Especial 2020.- PPGE - UNESC - ISSN 2317-2452

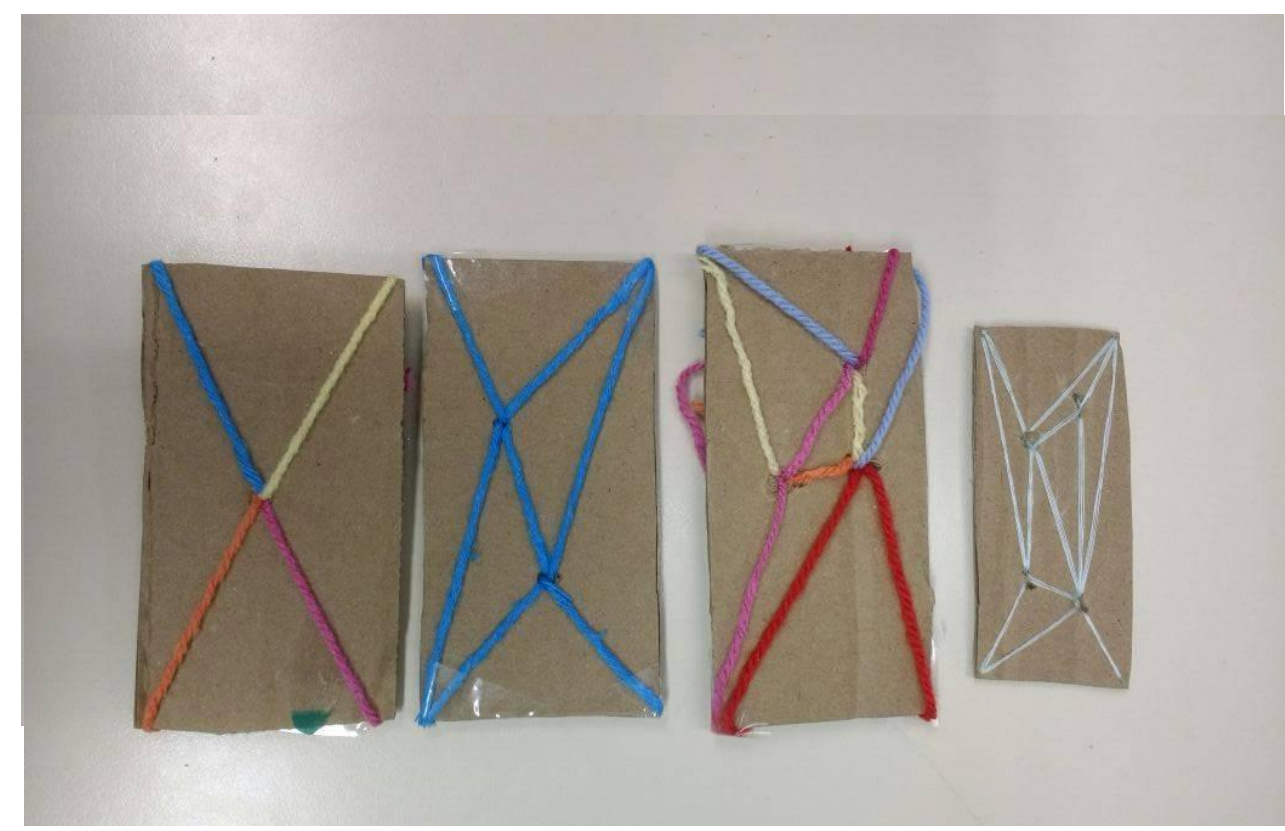

Fonte: Dos autores, 2017.

Conforme apresentado na imagem anterior, a atividade consistiu em primeiramente fazer um furo no papelão e representar quantos triângulos são possíveis formar, depois dois e assim sucessivamente. Porém, observou-se que, além de parecida com a atividade anterior, uma vez que utiliza-se praticamente os mesmos materiais, a forma proposta dificultaria prender a lã aos vértices e mesmo com fita adesiva não deixaria o fio bem alinhado. Assim sendo, decidiu-se fazer recortes, conforme mostra a Figura 4:

FIGURA 4: Sequência de pontos 


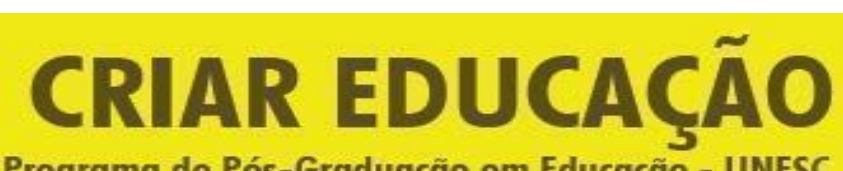

Revista do Programa de Pós-Graduação em Educação - UNESC

\section{Unesc PPG}

Criar Educação, Criciúma, v. 9, no22, Edição Especial 2020.- PPGE - UNESC - ISSN 2317-2452

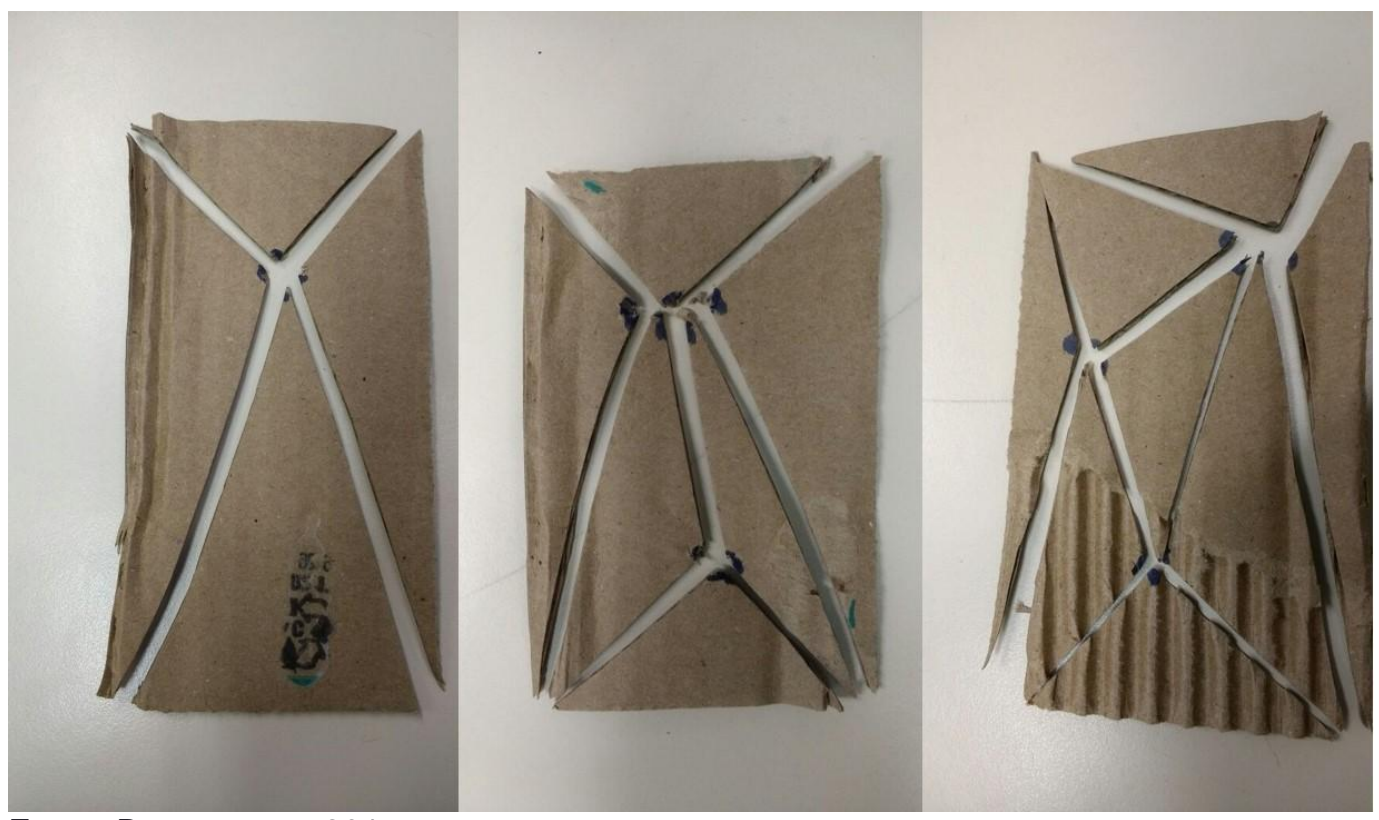

Fonte: Dos autores, 2017.

Após a construção, foi organizada a atividade para ser explorada com os professores da rede municipal envolvida:

Atividade: Sequência de pontos

Observar as marcas existentes em cada quadrilátero.

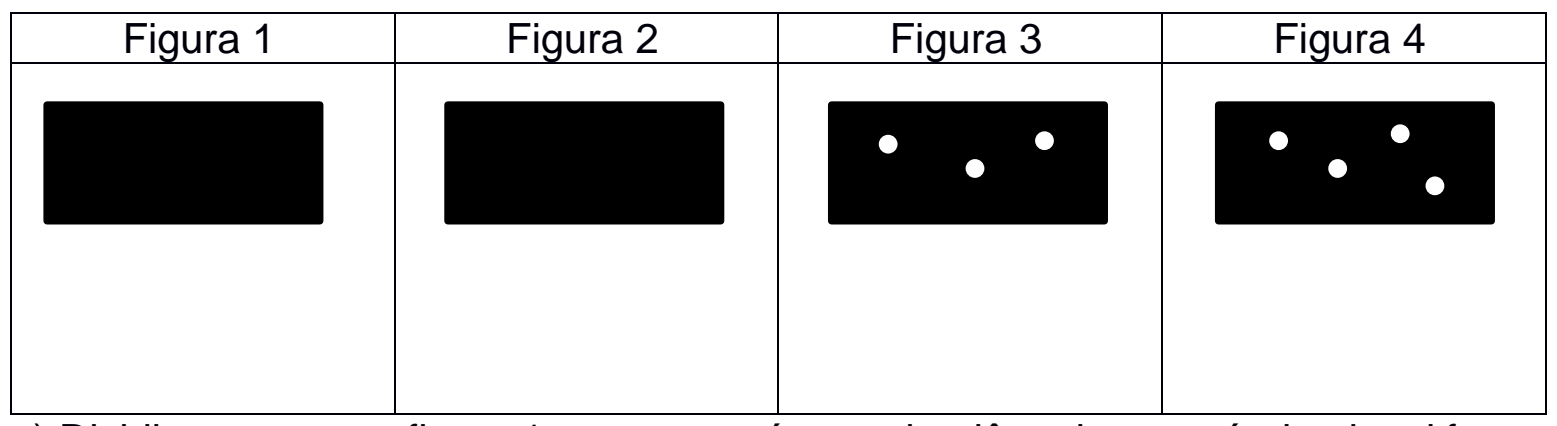

a) Dividir e recortar a figura 1 no menor número de triângulos possíveis, de tal forma que cada triângulo seja formado por dois vértices do quadrilátero e o ponto assinalado na figura. Quantos triângulos você recortou?

b) Dividir e recortar a figura 2 no menor número de triângulos possíveis, de tal forma que cada triângulo seja formado por dois vértices do quadrilátero e o ponto assinalado na figura. Quantos triângulos você recortou? 

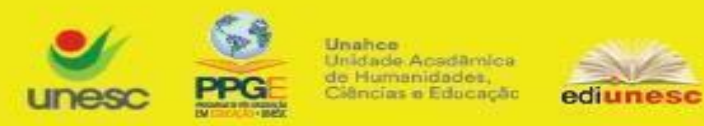

Criar Educação, Criciúma, v. 9, no2, Edição Especial 2020.- PPGE - UNESC - ISSN 2317-2452

c) Dividir e recortar a figura 3 no menor número de triângulos possíveis, de tal forma que cada triângulo seja formado por dois vértices do quadrilátero e o ponto assinalado na figura. Quantos triângulos você recortou?

d) Dividir e recortar a figura 4 no menor número de triângulos possíveis, de tal forma que cada triângulo seja formado por dois vértices do quadrilátero e o ponto assinalado na figura. Quantos triângulos você recortou?

e) Completar o quadro a seguir:

\begin{tabular}{|c|c|}
\hline Figura & Número mínimo de triângulos recortados \\
\hline 1 & \\
\hline 2 & \\
\hline 3 & \\
\hline$\ldots$ & \\
\hline
\end{tabular}

f) Escrever como você pensou para encontrar o número de triângulos da figura 5, completada no quadro anterior.

\section{Conclusões e propostas de continuidade}

Acredita-se que as atividades de investigação matemática têm muito a contribuir em sala de aula, pois são atividades investigativas que facilitam o aprendizado do aluno, através da exploração de diferentes conceitos matemáticos. Partindo desse pressuposto, Ponte (2003) defende a utilização das atividades matemáticas por possibilitar a criação do espírito de pesquisa, bem como o realce que é dado na argumentação, discussão, descoberta e avaliação.

Outro ponto a destacar é a importância do diálogo mútuo entre professores e alunos, durante a exploração das atividades investigativas. No momento de socialização das conjecturas ao grupo, os alunos podem validar ou não suas hipóteses, e isso é muito interessante, pois eles têm a oportunidade de interagir, socializar e descrever as experiências vivenciadas naquela atividade. Esse momento coloca os alunos no centro da ação, discussão, reflexão e consequentemente da aprendizagem. 


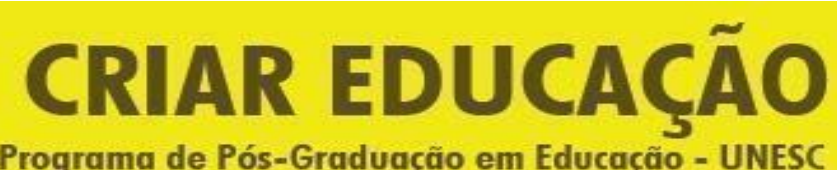

Revista do Programa de Pós-Graduação em Educação - UNESC

Criar Educação, Criciúma, v. 9, no2, Edição Especial 2020.- PPGE - UNESC - ISSN 2317-2452

Considera-se que o trabalho em equipe desenvolvido pelo grupo de pesquisadores contribuiu para o desenvolvimento de atividades inovadoras e condizentes com a proposta do projeto, pois se utilizou das experiências individuais para a construção de atividades com abrangência coletiva. Os objetos criados foram sendo incorporados às atividades, com afinidade e perspicácia para que os alunos pudessem compreender os objetivos das atividades, sobretudo em relação ao manuseio e identificação da simbologia representada pelas questões.

\section{Referências:}

ANASTASIOU, L. G. C.; ALVES, L. P. Processos de Ensinagem na Universidade: Pressupostos para as estratégias de trabalho em aula. Joinvile: Editora UNIVILLE, 2004.

BANDEIRA, Emanueli; NEHRING, Cátia Maria. Atividades Investigativas - Diálogos Iniciais. In: CNEM - Congresso Nacional de Educação Matemática, 2, 2011, ljuí. Anais ljuí: Unijuí, Jun.2011.

BANKS, Marcus. Dados visuais para pesquisa qualitativa. Tradução de José Fonseca. Porto Alegre: Artmed, 2009.

BARBOSA. P. M. O estudo da geometria. Revista Brasileira de Cartografia, $\mathrm{n} \cong 3$, 2008

BRASIL. Secretaria de Educação Fundamental. Parâmetros curriculares nacionais: Matemática. Brasília, 1998. 148 p.

BREDARIOL, C. C.; NACARATO, A. M. Raciocínios algébricos de alunos do 6ํa ao $8^{\circ}$. ano quando resolvem uma situação-problema envolvendo padrões. Anais... XI Encontro Nacional de Educação Matemática. Curitiba - Paraná, 18 a 21 de julho de 2013.

BROCARDO, J. Investigações na aula de matemática: A história da Rita. In I. C. Lopes, J. Silva, P. Figueiredo (EDs.), Actas ProfMat. p. 155-161. Lisboa: APM, 2001.

CASTRO, Juliana Facanali. Um estudo sobre a própria prática em um contexto de aulas de investigativas de Matemática. 2004. Dissertação (Mestrado Educação Matemática) - Faculdade de Educação, Universidade Estadual de Campinas, São Paulo, 2004.

COSTA, Lucélida. Vivências autoformativas no ensino de matemática: vida e formação em escolas ribeirinhas. Tese. Doutorado em Educação em Ciências e 


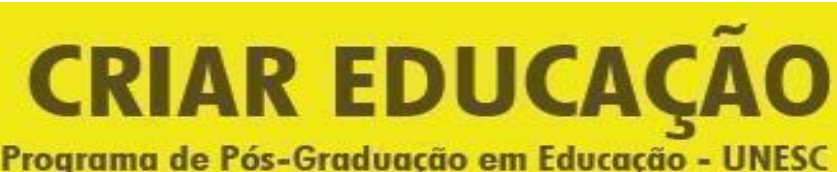

Revista do Programa de Pós-Graduação em Educação - UNESC

Criar Educação, Criciúma, v. 9, no2, Edição Especial 2020.- PPGE - UNESC - ISSN 2317-2452

Matemáticas, Instituto de Educação Matemática e Científica da UFPA Belém, PA, 2015.

FONSECA, R. C. da. Uma abordagem geométrica para cálculo do volume das quádricas. Dissertação de Mestrado - Vassouras, 2011. Disponível em: Acesso em 15 jul. 2017.

KIERAN, C. (2004). The core of algebra: Reflections on its main activities. In K. Stacey, H. Chick, \& M. Kendal (Eds.), The future of teaching and learning of algebra: The 12th ICMI Study (pp. 21-33). Boston: Kluwer.

KLUPPEL, G. T. e BRANDT C. F. Reflexões sobre o ensino da geometria em livros didáticos à Luz da teoria de representações semióticas segundo Raymond Duval. Anais... ANPED SUL. Seminário de Pesquisa em Educação da Região Sul, 2012.

LINS, R. C. e GIMENEZ, J. Perspectivas em aritmética e álgebra para o século XXI. Campinas, SP. Papirus, 1997.

LOMONATO, M.; PASSOS, C. L. B.; Discutindo resolução de problemas e exploraçãoinvestigação matemática: reflexões para 0 ensino de matemática. Zetetiké, FE/Unicamp - v. 19, n. 36 - jul/dez 2011.

LUNA, A. V. de; SOUZA, C. C. C. F. Discussões sobre o ensino de álgebra nos anos iniciais do Ensino Fundamental. In Educação Matemática em Pesquisa, São Paulo, v.15, Número Especial, pp.817-835, 2013.

NACARATO, A. M.; PASSOS, C. L. B. A Geometria nas Séries Iniciais: uma Análise sob a Perspectiva da Prática Pedagógica e da Formação de Professores. São Carlos: EdUFSCar, 2003.

OLIVEIRA, H., SEGURADO, M. I., PONTE, J. P. Tarefas de investigação em matemática: Histórias da sala de aula. In G. Cebola \& M. Pinheiro (Eds.), Desenvolvimento curricular em Matemática (p. 107-125). Lisboa: SEM-SPCE, 1998.

PASSOS, C. L. B. Representações, Interpretações e Prática Pedagógica: a Geometria na sala de aula. Tese (Doutorado em Educação Matemática) UNICAMP, Campinas/SP, 2000.

PONTE, J., BRANCO, N., MATOS, A. Álgebra no Ensino Básico. Lisboa: DGIDC-ME, 2009.

PONTE, J.P. Investigações matemáticas em Portugal. Investigar em educação, 2, 93169, 2003.

PONTE, João P. da; BROCARDO, Joana; OLIVEIRA, Hélia. Investigações matemáticas na sala de aula.Belo Horizonte: Autêntica, 2009. 
Criar Educação, Criciúma, v. 9, no2, Edição Especial 2020.- PPGE - UNESC - ISSN 2317-2452

SKOVSMOSE, Ole. Desafios da Educação Matemática Crítica. São Paulo: Papirus. 2008.

USISKIN, Zalman. Concepções sobre a álgebra da escola média e utilizações das variáveis. In: COXFORD, Arthur F.; SHULTE, Alberto P.(Org). As idéias da álgebra. São Paulo: Atual, 1995. 
Criar Educação, Criciúma, v. 9, no2, Edição Especial 2020.- PPGE - UNESC - ISSN 2317-2452 